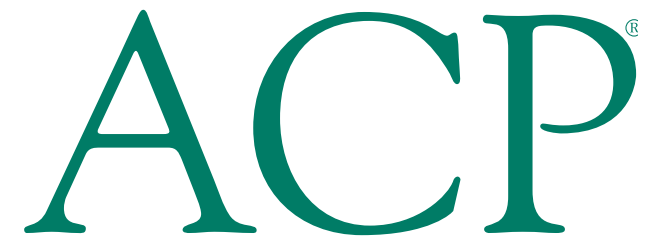

American College of Physicians

internal Medicine | Doctors for Adults

\title{
RACIAL AND ETHNIC
}

Disparities in Health Care,

UPDATED 2010 


\section{Racial and Ethnic Disparities in Health Care}

\section{A Summary of a Position Paper Approved by the ACP Board of Regents, April 2010}

\section{What Are the Sources of Racial and Ethnic Disparities in Health Care?}

The Institute of Medicine defines disparities as "racial or ethnic differences in the quality of health care that are not due to access-related factors or clinical needs, preferences, and appropriateness of intervention." Racial and ethnic minorities tend to receive poorer quality care compared with nonminorities, even when access-related factors, such as insurance status and income, are controlled.

The sources of racial and ethnic health care disparities include differences in geography, lack of access to adequate health coverage, communication difficulties between patient and provider, cultural barriers, provider stereotyping, and lack of access to providers. In addition, disparities in the health care system contribute to the overall disparities in health status that affect racial and ethnic minorities.

\section{Why is it Important to Correct These Disparities?}

The problem of racial and ethnic health care disparities is highlighted in various statistics:

- Minorities have less access to health care than whites. The level of uninsurance for Hispanics is 34\% compared with $13 \%$ among whites.

- Native Americans and Native Alaskans more often lack prenatal care in the first trimester.

- Nationally, minority women are more likely to avoid a doctor's visit due to cost.

- Racial and ethnic minority Medicare beneficiaries diagnosed with dementia are $30 \%$ less likely than whites to use antidementia medications.

ACP is strongly committed to advocating for increased access to quality health care for all, regardless of race, ethnicity, socioeconomic status, or other factors. Accordingly, the mission of ACP is "to enhance the quality and effectiveness of health care by fostering excellence and professionalism in the practice of medicine." The College believes that racial and ethnic disparities in health care are unacceptable and supports policies that increase access to health care for all, invest in preventive care, create a more diverse health care workforce, address social determinants of health, and expand research into the causes and solutions regarding racial and ethnic health disparities.

\section{Key Findings and Recommendations from the Paper}

ACP recommends the following:

- Providing all legal residents with affordable health insurance is an essential part of eliminating racial and ethnic disparities in health care. 
- All patients, regardless of race, ethnic origin, gender, nationality, primary language, socioeconomic status, sexual orientation, cultural background, age, disability, or religion, deserve high-quality health care.

- As our society increasingly becomes racially and ethnically diverse, physicians and other health care professionals need to acknowledge the cultural, informational, and linguistic needs of their patients. Health literacy among racial and ethnic minorities must be strengthened in a culturally and linguistically sensitive manner.

- Physicians and other health care professionals must be sensitive to cultural diversity among patients and recognize that preconceived perceptions of minority patients may play a role in their treatment and contribute to disparities in health care among racial and ethnic minorities. Such initiatives as cultural competency training should be incorporated into medical school curricula to improve cultural awareness and sensitivity.

- The health care delivery system must be reformed to ensure that patient-centered medical care is easily accessible to racial and ethnic minorities and physicians are enabled with the resources to deliver quality care.

- A diverse health care workforce that is more representative of the patients it serves is crucial to promote understanding among physicians and other health care professionals and patients, facilitate quality care, and promote equity in the health care system.

o Education of minority students at all educational levels, especially in the fields of math and science, needs to be strengthened and enhanced to create a larger pool of qualified minority applicants for medical school.

o Medical and other health professional schools should revitalize efforts to improve matriculation and graduation rates of minority students. ACP supports policies that allow institutions of higher education to consider a person's race and ethnicity as one factor in determining admission in order to counter the impact of current discriminatory practices and the legacy of past discrimination practices. Programs that provide outreach to encourage minority enrollment in medical and health professional schools should be maintained, reinstated, and expanded.

o Medical schools need to increase efforts to recruit and retain minority faculty.

o Efforts should be made to hire and promote minorities in leadership positions in all areas of the health care workforce.

o Funding should be continued and increased for programs and initiatives that work to increase the number of physicians and other health care professionals in minority communities.

- Social determinants of heath are a significant source of health disparities among racial and ethnic minorities. Inequities in education, housing, job security, and environmental health must be erased if health disparities are to be effectively addressed.

- Efforts must be made to reduce the effect of environmental stressors that disproportionately threaten to harm the health and well-being of racial and ethnic communities.

- More research and data collection related to racial and ethnic health disparities is needed to empower stakeholders to better understand and address the problem of disparities.

\section{For More Information}

This issue brief is a summary of Racial and Ethnic Disparities in Health Care, Updated 2010. The full paper is available at http://www.acponline.org/advocacy/where we stand/access/racial disparities.pdf. 



\title{
RACIAL AND ETHNIC DisPaRITIES IN Health Care, Updated 2010
}

\author{
A Position Paper of the \\ American College of Physicians \\ May 13, 2010
}

This paper, written by Ryan Crowley, was developed for the Health and Public Policy Committee of the American College of Physicians: Richard Neubauer, MD, FACP, Chair; David Fleming, MD, FACP, Vice-Chair; David L. Bronson, MD, FACP; Robert M. Centor, MD, FACP; Robert A. Gluckman, MD, FACP; Richard P. Holm, MD, FACP; Mark Liebow, MD, FACP; Mark E. Mayer, MD, FACP; Robert McLean, MD, FACP; Kenneth Musana, MBchB, MSC, FACP; P. Preston Reynolds, MD, FACP; Matthew Rudy, Student; and Baligh Yehia, MD, Associate. It was approved by the Board of Regents on 12 April 2010. 
How to cite this paper:

American College of Physicians. Racial and Ethnic Disparities in Health Care, Updated 2010. Philadelphia: American College of Physicians; 2010: Policy Paper. (Available from American College of Physicians, 190 N. Independence Mall West, Philadelphia, PA 19106.)

Copyright (O2010 American College of Physicians.

All rights reserved. Individuals may photocopy all or parts of Position Papers for educational, not-for-profit uses. These papers may not be reproduced for commercial, for-profit use in any form, by any means (electronic, mechanical, xerographic, or other) or held in any information storage or retrieval system without the written permission of the publisher.

For questions about the content of this Policy Paper, please contact ACP, Division of Governmental Affairs and Public Policy, Suite 700, 25 Massachusetts Avenue NW, Washington, DC 20001-7401; telephone 202-261-4500. To order copies of this Policy Paper, contact ACP Customer Service at 800-523-1546, extension 2600, or 215-351-2600. 


\section{Executive Summary}

Overwhelming evidence shows that racial and ethnic minorities are prone to poorer quality health care than white Americans, even when factors such as insurance status are controlled. As the nation's population continues to grow and diversify, the health care system will have to change and adjust to meet the needs of an increasingly multicultural patient base. In 2003, the American College of Physicians, which is now the largest medical specialty society in the United States with over 129,000 physicians and medical student members, released the paper Racial and Ethnic Disparities in Health Care (www.acponline.org/ppvl/policies/e000904.pdf). The paper provided a number of recommendations on how the gulf between racial and ethnic minority patients and their white counterparts can be closed. Unfortunately, while progress has been made in some areas, the issue of racial and ethnic disparities remains a difficult and complex problem to address. This update of the 2003 paper adopts recommendations that still need attention - such as improving access to health insurance among minorities - and also notes where progress has been made.

The sources of racial and ethnic disparities are rooted not only in the nation's dysfunctional health care system but also in a number of societal determinants that are touched upon in this paper. An individual's environment, their income, level of education, and other factors all affect health or reflect a person's health status. If racial and ethnic disparities are to be successfully addressed, the nation must make a concerted effort to improve the stressors existing both within and outside of the health care system itself. In addition to the College's continued support for a number of recommendations outlined in the 2003 paper, ACP recommends the following:

\section{Recommendations}

Position 1: Providing all legal residents with affordable health insurance is an essential part of eliminating racial and ethnic disparities in health care.

Position 2: All patients, regardless of race, ethnic origin, gender, nationality, primary language, socioeconomic status, sexual orientation, cultural background, age, disability, or religion, deserve high-quality health care.

Position 3: As our society increasingly becomes racially and ethnically diverse, physicians and other health care professionals need to acknowledge the cultural, informational, and linguistic needs of their patients. Health literacy among racial and ethnic minorities must be strengthened in a culturally and linguistically sensitive manner.

Position 4: Physicians and other health care professionals must be sensitive to cultural diversity among patients and recognize that preconceived perceptions of minority patients may play a role in their treatment and contribute to disparities in health care among racial and ethnic minorities. Such initiatives as cultural competency training should be incorporated into medical school curriculae to improve cultural awareness and sensitivity. 
Position 5: The health care delivery system must be reformed to ensure that patient-centered medical care is easily accessible to racial and ethnic minorities and physicians are enabled with the resources to deliver quality care.

Position 6: A diverse health care workforce that is more representative of the patients it serves is crucial to promote understanding among physicians and other health care professionals and patients, facilitate quality care, and promote equity in the health care system.

A. Education of minority students at all educational levels, especially in the fields of math and science, needs to be strengthened and enhanced to create a larger pool of qualified minority applicants for medical school.

B. Medical and other health professional schools should revitalize efforts to improve matriculation and graduation rates of minority students. ACP supports policies that allow institutions of higher education to consider a person's race and ethnicity as one factor in determining admission in order to counter the impact of current discriminatory practices and the legacy of past discrimination practices. Programs that provide outreach to encourage minority enrollment in medical and health professional schools should be maintained, reinstated, and expanded.

C. Medical schools need to increase efforts to recruit and retain minority faculty.

D. Efforts should be made to hire and promote minorities in leadership positions in all arenas of the health care workforce.

E. Funding should be continued and increased for programs and initiatives that work to increase the number of physicians and other health care professionals in minority communities.

Position 7: Social determinants of health are a significant source of health disparities among racial and ethnic minorities. Inequities in education, housing, job security, and environmental health must be erased if health disparities are to be effectively addressed.

Position 8: Efforts must be made to reduce the effect of environmental stressors that disproportionately threaten to harm the health and well-being of racial and ethnic communities.

Position 9: More research and data collection related to racial and ethnic health disparities is needed to empower stakeholders to better understand and address the problem of disparities. 


\section{Background}

Racial and ethnic minorities tend to receive poorer quality care compared with nonminorities, even when access-related factors, such as insurance status and income, are controlled. ${ }^{1}$ The Institute of Medicine (IOM) defines disparities as "racial or ethnic differences in the quality of health care that are not due to access-related factors or clinical needs, preferences, and appropriateness of intervention." ${ }^{2}$ While other entities, such as the World Health Organization, have adopted a different view of what constitutes a disparity, major stakeholders agree that such disparities are unjust and need to be addressed. ${ }^{3}$

The problem of racial and ethnic health care disparities is highlighted in various statistics:

- Minorities have less access to health care than whites. The level of uninsurance for Hispanics is 34\% compared with $13 \%$ among whites. ${ }^{4}$

- Native Americans and Native Alaskans more often lack prenatal care in the first trimester.

- Nationally, minority women are more likely to avoid a doctor's visit due to cost. ${ }^{5}$

- Racial and ethnic minority Medicare beneficiaries diagnosed with dementia are $30 \%$ less likely than whites to use antidementia medications. ${ }^{6}$

The sources of racial and ethnic health care disparities include differences in geography, lack of access to adequate health coverage, communication difficulties between patient and provider, cultural barriers, provider stereotyping, and lack of access to providers. Closing the health care disparities gap is a difficult, multifaceted task. A study that surveyed 14 racial and ethnic minority subgroups concluded that health disparities could be narrowed by providing minorities with better health insurance coverage, more adequate language skills and assistance, and higher incomes. ${ }^{7}$ However, the authors noted that other important factors, such as stereotyping, biases, and uncertainty in the provision of medical care, would also need to be explored. Closing the disparity gap is not only morally and professionally imperative, it remains a glaring civil rights injustice that must be addressed. Since the 1990s, federal government, health insurers, and other stakeholders have taken an increased interest in addressing health disparities among minority groups. For instance, the Healthy People 2010 initiative highlighted the elimination of racial and ethnic health disparities as a prominent public health goal for the next decade.

\section{Disparities in Health Status}

It should be noted that disparities in the health care system contribute to the overall disparities in health status that affect racial and ethnic minorities. An individual's health status is influenced not only by the health care system, but also environmental, genetic, and social determinants. Racial and ethnic minorities have present-day health statistics that reflect historical values for whites. For instance, infant mortality rates among minority groups lag behind those of whites. Among African Americans, the infant mortality rate was 2.4 times greater than that of the white population. ${ }^{8}$ In 2005 (the last year data for all countries were available), the United States ranked 29th in the world in infant mortality largely due to the troubling health disparities among racial and ethnic minorities. ' In addition, African-American men and women have lower life expectancies than whites. ${ }^{10}$ One study found that closing the black-white mortality gap would eliminate a startling " 83,000 excess deaths per year among African Americans.” ${ }_{11}$ 
Although this paper focuses on the problems within the health care system that cause and exacerbate health disparities, one cannot discount the social determinants that affect health. The IOM found that "racial and ethnic disparities in health care occur in the context of broader historic and contemporary social and economic inequality, and [that] racial and ethnic discrimination [persists] in many sectors of American life" despite legal, legislative, and administrative efforts to eliminate them. Residential segregation, lack of access to quality education, and barriers to economic opportunity, among others, are all factors that play a major part in determining an individual's health status. . $^{12,13,14}$ If disparities in health are to be alleviated, a comprehensive effort to address all factors that influence health status must be undertaken.

The ACP is strongly committed to advocating for increased access to quality health care for all regardless of race, ethnicity, socioeconomic status, or other factors. Accordingly, the mission of ACP is, "To enhance the quality and effectiveness of health care by fostering excellence and professionalism in the practice of medicine." The College believes that racial and ethnic disparities in health care are unacceptable and supports policies that increase access to health care for all, invest in preventive care, create a more diverse health care workforce, address societal determinants of health, and expand research into the causes and solutions regarding racial and ethnic health disparities. Accordingly, strategic objectives of the College include "improving access to care and eliminating disparities, with a focus on expanding health insurance coverage." 15

\section{Position 1: Providing all legal residents with affordable health insur- ance is an essential part of eliminating racial and ethnic disparities in health care.}

The United States has made great strides over the past 50 years in improving access to health care. The number of Americans with access to health insurance, provided as a benefit through their employer, through a public program such as Medicare or Medicaid, or by other means, has increased dramatically since World War II, although 46 million people currently lack health insurance coverage. Advancements in medicine, improvements in the public health infrastructure, and other factors have dramatically increased life expectancy. However, for many people, especially in communities of color, the benefits of such medical advancements - particularly due to lack of access to care - have not been fully realized. While the factors that cause racial and ethnic health care disparities are complex and often extend outside of the boundaries of health policy, perhaps the most significant variable influencing disparities is insurance status. An individual with insurance is much more likely to access care. Minorities are more likely to be uninsured than whites, even when accounting for work status. ${ }^{16}$ Nearly $32 \%$ of Native Americans/Native Alaskans are uninsured, followed by about $31 \%$ of Hispanics; whereas, about $11 \%$ of whites are uninsured. ${ }^{17}$ A literature review conducted for the Kaiser Family Foundation concluded that health insurance was the single most significant factor explaining racial disparities in having a usual source of care. ${ }^{18}$ The 2007 National Health Disparities Report concurs, stating that based "on analyses of a set of core quality measures, the factor most consistently related to better quality is whether a patient is insured." ${ }^{19}$ However, even within the uninsured population, racial and ethnic minorities fare worse than whites in their ability to access health care. ${ }^{20}$

Lack of access to adequate insurance has severe consequences related to a person's health status, their ability to receive preventive care, and their ability 
to manage health problems, such as chronic disease. At the individual level, health insurance improves access to care, health outcomes, and quality of life and insulates against high medical expenses; on a larger level, health insurance coverage influences provider practice viability, employee productivity, and community health. ${ }^{21}$ An overwhelming body of evidence suggests that those without insurance have worse health outcomes and die sooner than those with health coverage..$^{22}$ For instance, over one third of the uninsured have a chronic disease and are six times less likely to receive adequate care for an illness than those with insurance. ${ }^{23}$ Over the past decade, the number of individuals with insurance has declined while the cost of health coverage has grown considerably, making it more difficult for employers and individuals to access coverage and care. The declining number of jobs offering insurance is more of a problem for minority groups. Three fifths $(60 \%)$ of the population under the age of 65 receives coverage through employers. ${ }^{24}$ However, minorities are less likely than whites to be offered the benefit. Nearly $70 \%$ of nonelderly whites receive employer-based insurance while only $40 \%$ of Hispanics receive such coverage. ${ }^{25}$ Only 48\% of African Americans and 43\% of Native Americans/Native Alaskans receive health insurance through their employer. However, Asian Americans/ Pacific Islanders are nearly as likely as whites to receive employer-based insurance. ${ }^{26}$ Especially during economic downturns, Hispanics and black persons report more difficulty affording health coverage compared with whites and are more likely to skip or postpone care due to cost. ${ }^{27}$ Even among higher income populations, racial and ethnic minorities are less likely to be insured; in 20072008, almost one third of Hispanic families earning 400\% federal poverty level (FPL) or above lacked coverage compared with $16 \%$ of whites. ${ }^{28}$

Partly because of the difficulty in accessing affordable private health insurance, racial and ethnic minorities are more likely to receive coverage through public programs. According to 2007 U.S. Census statistics, half of the nation's nearly 40 million Medicaid enrollees were racial and ethnic minorities. ${ }^{29}$ However, Medicaid, a program paid for by federal and state governments, is often vulnerable in economic downturns, as states with budget problems curb coverage and decrease enrollment despite increasing need. For instance, a 1 percentage point rise in the unemployment rate would increase Medicaid and State Children's Health Insurance Program enrollment by 1 million. Despite the greater need for public health programs in times of economic distress, it is predicted that states needing to balance their budgets would be forced to reduce Medicaid and Children's Health Insurance Program (CHIP) spending by 3 to $4 \%$ for every $1 \%$ increase in unemployment. ${ }^{30}$ Disparities are also present in aspects of Medicare. African Americans are less likely than whites to purchase supplemental Medicare coverage. ${ }^{31}$ Further, more minority Medicare beneficiaries than white beneficiaries are considered dual-eligible, receiving coverage from both the Medicare and Medicaid programs, leaving them particularly vulnerable to fluctuations in federal and state spending and policy decisions. ${ }^{32}$

While many racial and ethnic minorities are enrolled in the Medicaid and CHIP programs, many more are eligible for such coverage but are not enrolled, either because they are unaware of their eligibility or face other barriers, such as limited English proficiency and enrollment process complexities. For instance, more than $80 \%$ of uninsured African-American children and $70 \%$ of uninsured Latino children are eligible for Medicaid or CHIP coverage. ${ }^{33}$ Streamlined enrollment processes coupled with aggressive outreach efforts to increase participation among eligible minority groups are essential so more of the uninsured can get health insurance coverage. Such efforts should be sensitive to the linguistic and cultural needs of the targeted populations. ${ }^{34}$ Federal 
legislation to reauthorize the CHIP program included increased funding for outreach and enrollment efforts for the Medicaid and CHIP programs, including specific funding for Indian Health Service Providers and Urban Indian Organizations to enroll Native American children. ${ }^{35}$ Streamlined citizenship documentation requirements and electronic enrollment processes were also included in the CHIP reauthorization to improve enrollment.

ACP has long supported efforts to expand health coverage to all. In the ACP paper Achieving Affordable Health Insurance Coverage for All Within Seven Years, the College recommended that Medicaid be expanded to cover all individuals with incomes at or below $100 \%$ of FPL, that tax-based subsidies be made available to the uninsured with incomes up to $200 \%$ of FPL, and that new options be made available to small businesses to purchase coverage for their employees. ${ }^{36} \mathrm{ACP}$ also recommends that tax credit recipients be permitted to purchase coverage through state purchasing group arrangements modeled after the Federal Employees Health Benefits Program (FEHBP). In the ACP paper Achieving A High Performance Health Care System with Universal Access, the College recommended that federal and state governments consider adopting one or the other of two pathways to achieving universal coverage: either a single-payer system in which one governmental entity is the sole third-party payer of health care costs, or a pluralistic system with a legal guarantee that all individuals have access to coverage with sufficient government subsidies and funded coverage for those who cannot afford to purchase coverage through the private sector. ${ }^{37}$

Position 2: All patients, regardless of race, ethnic origin, gender, nationality, primary language, socioeconomic status, sexual orientation, cultural background, age, disability, or religion, deserve highquality health care.

In addition to expanding access to health insurance, the quality of care that minority patients receive must also be improved. According to the 2008 National Healthcare Disparities report issued by the Agency for Healthcare Research and Quality (AHRQ), a number of disparities related to the quality of care have been exacerbated since the first report in 2003:

- African Americans fared significantly worse on 19 of 38 core quality-ofcare measures considered in the report, and had better care than whites on only 4 of the core report measures.

- African Americans are more likely to report poor provider-patient communication than white patients.

- White patients more often receive recommended advice on exercise and recommended care for heart attack than Hispanic patients.

- Native Americans/Native Alaskans are less likely than whites to receive colorectal cancer screening.

- Asian Americans are less likely than whites to receive recommended hospital care for pneumonia.

The health care quality gap is evident, for instance, in the provision of cardiac care. African-American patients are less likely than their white counterparts to receive evidence-based procedures following hospitalization for heart failure, stroke or acute myocardial infarction and receive delayed access to new cardiac technology, such as drug-eluting stents. ${ }^{38}$ The Kaiser Family Foundation and the American College of Cardiology conducted a comprehensive review of 81 
studies investigating potential racial and ethnic disparities in cardiac care. The review found that 68 of the 81 studies discovered evidence of disparities in the cardiac care received by at least one minority group under study. The strong studies found that even when clinical and socioeconomic factors were controlled for, African-American patients are less likely to receive certain procedures than white patients, particularly diagnostic services, revascularization procedures, and thrombolytic therapy. ${ }^{39}$ Disparities also appear in stage of cancer at diagnosis and cancer survival rates. African-American patients are more likely than white patients to receive a late-stage cancer diagnosis, which undermines the probability of survival. Such disparities exist even among Medicare-aged patients. ${ }^{40}$

In addition, a study by Blendon et al. found that 10 of 14 ethnic subgroups were less likely than whites to believe that the physician care they received was "excellent" or "good." ${ }^{41}$ According to the AHRQ, disparities in the quality of care received by racial and ethnic minorities are more likely to be the same or worsening, rather than improving. ${ }^{42}$ While the issue of health care delivery system reform is discussed at length under Position 6, ACP strongly believes that all individuals, regardless of racial or ethnic background, should have access to quality care. In the ACP white paper Controlling Health Care Costs While Promoting the Best Possible Health Outcomes, the College recommends that clinically effective care be encouraged and that such care should be based on comparative effectiveness research and implementation of health information technology. ${ }^{43}$

\section{Position 3: As our society increasingly becomes racially and ethnically diverse, physicians and other health care professionals need to acknowledge the cultural, informational, and linguistic needs of their patients. Health literacy among racial and ethnic minorities must be strengthened in a culturally and linguistically sensitive manner.}

Culturally competent care ensures that all patients receive high-quality, effective care irrespective of cultural background, language proficiency, socioeconomic status, and other factors that may be informed by a patient's race or ethnicity. ${ }^{44}$ Lack of cultural awareness can undermine the doctor-patient relationship. While only half of all patients adhere to medical or prescription instructions offered by clinicians, rates of adherence are significantly lower for racial and ethnic minorities. ${ }^{45}$ Cultural sensitivities must be understood and respected at all levels of a patient's care experience. The U.S. Health and Human Services Administration's Office of Minority Health has identified a number of standards that health care organizations and individual providers are encouraged to use when integrating culturally competent care techniques into practice. Among the recommendations are that providers should ensure that patients receive from all staff members "effective, understandable, respectful" care compatible with cultural and linguistic preferences; that a strategy to recruit a diverse staff and practice leadership reflecting the patient population be implemented; and that staff receive ongoing cultural competency training. ${ }^{46}$ Cultural competency is a key part of delivering patient-centered care; both concepts stress respect for the patient, clear communication, shared decision making, and building of the doctor-patient relationship. ${ }^{47}$

As the nation's population diversifies, cultural competency will become more important as clinicians are confronted with different belief systems that influence their ability or patient receptivity to provider recommendations. According to one survey, insurers, government entities, and educators expressed recognition and support for cultural competency training and utilization 
because of its potential to close the gap on racial and ethnic health disparities, improve health outcomes, and increase access to high-quality care for vulnerable populations. ${ }^{48}$

\section{Language Access}

Almost a quarter of Americans speak a language at home other than English. Over 300 languages are spoken in the United States, with Spanish being the most common language spoken other than English. ${ }^{49}$ Communication is a critical component of the doctor-patient relationship. Linguistic barriers make it difficult for trust to be established and physician recommendations to be fulfilled. Those with limited English proficiency (LEP) often receive poorer quality care and have worse access to care than fluent patients. ${ }^{50}$ Limited English proficiency patients seeking psychiatric care are more often diagnosed with severe psychopathology and are more likely to disregard medical advice and leave the hospital prior to discharge.$^{51}$ In addition, LEP patients are less likely than fluent speakers to use primary care and preventive services. Seventy percent of internal medicine physicians believe that LEP patients have a worse understanding of basic health information than fluent speakers. ${ }^{52}$

Communication barriers are a significant problem for many physicians, especially those who provide care frequently to Medicaid and other public insurance program beneficiaries. In one survey, $63 \%$ of hospitals and $54 \%$ of internal medicine physicians reported treating LEP patients at least weekly and $84 \%$ of federally qualified health centers cared for LEP patients daily. ${ }^{53}$ According to an ACP survey, internists reported seeing LEP patients speaking nearly 80 dialects and languages. ${ }^{54}$ Even after the influential 2002 IOM report Unequal Treatment highlighted the difficulties of communication between physicians and other health providers and patients with limited English proficiency, the problem has worsened among some groups. ${ }^{55}$ The IOM report recommended that health system interventions, such as use of interpreters, could improve communication for LEP patients. Federal and state laws have been enacted to facilitate and require access to interpretive and/or translation services. The Department of Health and Human Services and the U.S. Supreme Court have interpreted Title VI of the Civil Rights Act to protect citizen LEP minorities by ensuring that they have access to health care providers receiving federal funding. ${ }^{56}$ While a number of federal and state laws are in place to ensure that LEP patients have access to interpreters, such laws are insufficiently enforced and gaps in services persist. ${ }^{57}$ For instance, one emergency department survey found that $87 \%$ of patients without an interpreter thought these services would have been valuable during the encounter..$^{58}$ Additionally, $61 \%$ of physicians surveyed stated that it was much more difficult to provide patient care to LEP patients when language services were not available..$^{59}$ Children may be the only family members who speak English, but they should not be used as interpreters, as this may place them in situations beyond their maturity to handle. Health care professionals should also use caution when using family members or friends of patients as interpreters.

All payers should provide funding for linguistic and interpretive materials and personnel. Currently, few private insurers cover the cost of language services and Medicare does not reimburse for interpreters. ${ }^{60}$ Only 12 states and the District of Columbia provide funding for interpreters for Medicaid and CHIP beneficiaries. ${ }^{61}$

ACP recognizes the important role of interpreters during medical encounters for increasing access to care for ethnic and racial minorities. However, the 
cost of providing these services could be exorbitant, and keeping interpreters on staff would be impractical for most physician practices serving multiple ethnic and minority populations speaking many different languages. The College recommends that language services be available to improve the provision of health care services to LEP patients, that Medicare reimburse clinicians for the expense of language services and the additional time involved in providing clinical care for LEP patients, and that a national clearinghouse be established to provide translated documents and patient education materials. ${ }^{62}$

In 2004, the College released 11 principles to raise awareness of the issue and guide stakeholders in their efforts to address this important matter. The lead principle states that "(e)ffective communication between health care providers and patients is essential to facilitating access to care, reducing health disparities and medical errors, and assuring a patient's ability to adhere to treatment plans." ${ }^{63}$ The principles were endorsed by a number of other organizations, including the American Hospital Association, the National Council of La Raza, and the Joint Commission on the Accreditation of Health Care. The College continues to emphasize the importance of improving communication between providers and LEP patients and maintains that this goal is fundamental to reducing health disparities among minority patients.

\section{Health Literacy}

Health literacy is defined as "the degree to which individuals have the capacity to obtain, process, and understand basic health information and services needed to make appropriate health decisions." ${ }^{64}$ Even when a language barrier is not present between doctor and patient, many patients do not understand health-related recommendations conveyed by health care professionals. According to a report by the IOM, nearly half of all Americans have difficulty understanding and acting upon health information, such as insurance forms, prescription drug labels, and other medical information. ${ }^{65}$ The IOM found that individuals with limited health literacy are more likely to be hospitalized than those with adequate literacy and to report a lower health status, and that individuals with low health literacy and chronic disease are less likely to adhere to disease management regimens. ${ }^{66,67}$ Health illiteracy is most common among older adults, individuals with low education levels, and LEP patients. Some racial and ethnic minorities are particularly likely to have low health literacy. For instance, only $55 \%$ of Central/South American patients report that their doctor explains things in a way they understand compared with $81 \%$ of whites. ${ }^{68}$ Physicians and other clinicians can improve the understanding and adherence to medical orders by asking patients to demonstrate use of their medication regimen and by having patients restate recommendations in their own words. ${ }^{69}$ Such exercises have been shown to improve recall and understanding during the encounter. ${ }^{70}$ A survey of federally qualified health centers, free clinics, and migrant health facilities found that when clinicians used plain language, used illustrations, and sat face-to-face with the patient, communication was greatly improved. ${ }^{71}$

The fragmented nature of the nation's health care system makes medical care more difficult to navigate and understand. Patients, especially those with chronic diseases, are often cared for by nurses, primary care physicians, and specialists. Better patient engagement by the clinician and staff; clear communication that is easily understandable to those with limited literacy; and creating treatments based on a patient's level of health literacy while acknowledging cultural inputs and language needs are all ways that may improve patient outcomes. $^{72,73}$ 
ACP has supported legislative efforts to improve health literacy. In 2007 the College endorsed the National Health Literacy Act, which would improve strategic planning, research, and coordination to strengthen the public's knowledge of accurate health information.

Position 4: Physicians and other health care professionals must be sensitive to cultural diversity among patients and recognize that preconceived perceptions of minority patients may play a role in their treatment and contribute to disparities in health care among racial and ethnic minorities. Such initiatives as cultural competency training should be incorporated into medical school curriculae to improve cultural awareness and sensitivity.

The IOM's Unequal Treatment report discussed the shameful legacy of discrimination and racism that has plagued our nation's health care system. Past segregation of the health care delivery system, from hospitals to small physician practices, has persisted in the minds of racial and ethnic minority patients, and the wounds of this tarnished legacy remain. Minority patients are more likely than their white counterparts to perceive racism in the health care system and are more prone to delay care because of distrust. ${ }^{74}$

Unfortunately, whether conscious or not, bias and prejudice do play a role in the delivery of health care to racial and ethnic minorities. In a study of physician perceptions of minority patients, physicians surveyed rated AfricanAmerican patients as less intelligent, less educated, more likely to abuse alcohol and drugs, more likely to fail to comply with medical advice and less likely to participate in cardiac rehabilitation than white patients. ${ }^{75}$ Preconceived determinations made by health professionals may inform and undermine the delivery of appropriate care. Physicians must be aware of their preconceived perceptions of minority patients when delivering care to patients and should deliver care based on clinical evidence of effectiveness. While there is no panacea to erasing bias and prejudice in the delivery of health care, efforts to strengthen understanding through cultural competency training may improve relations among minority patients and their physician or other health care professionals.

\section{Cultural Competency Training}

Racial and ethnic minorities tend to receive less clinical information from their physician, often believe that their physician is not aware of alternative/folk medicine therapies used by their community, and tend to feel more removed from the decision-making process than white patients. Research has also found that Hispanic, Asian, and African-American patients have diminished trust and feel less respect from their physicians than white patients. ${ }^{76}$ Evidence suggests that the practice of medicine can have a dehumanizing effect on clinicians and that physicians may become so absorbed by the "culture of biomedicine" that it may become difficult to relate to those with differing views on the practice of medicine. ${ }^{77,78}$ Evidence that cultural competency training can lead to improved patient outcomes and fewer liability claims exists, although more research is needed. ${ }^{79}$

To understand and treat racial and ethnic minorities better, physicians must engage in cultural competency training at all medical education levels. An increasing number of medical schools offer pathways to cultural competence development, but more needs to be done. ${ }^{80}$ Surveys report that while nearly all residents believe that addressing cultural issues is moderately or very important, 
about one in five felt they were not prepared to care for individuals whose beliefs are at odds with Western medicine, new immigrants, or those whose religious beliefs affect treatment. ${ }^{81}$ Proper patient engagement takes time, and many resident physicians who provide care for racial and ethnic minorities have expressed concern that time constraints and other pressures related to day-today medical practice do not facilitate cross-cultural communication and understanding. ${ }^{82}$ Many residents also report that they lack professional mentorship in the area of cross-cultural care and receive little evaluation of skills. Other evidence suggests that existing cultural competency measures are insufficient to produce meaningful change among providers. ${ }^{83}$

In the ACP 2003 paper Racial and Ethnic Disparities in Health Care, the College recommended that the Liaison Committee on Medical Education and the Accreditation Council for Graduate Medical Education develop competencies of cultural knowledge for medical schools and residency programs and require these competencies, as well as guidance on how to accomplish them, of all medical schools and residency programs. Since that paper was published, the LCME has issued an accreditation standard requiring all medical schools to incorporate cultural competence into their curricula. ACGME has issued its own standards. ${ }^{84}$ The Association of American Medical Colleges has developed the Tool for Assessing Cultural Competence Training to assist medical schools in developing and integrating cultural competency content into school curriculum..$^{85}$

Increased interest and validation of the importance of cultural competence by the medical community is encouraging. Better understanding between those of different cultures and primary languages is critical to closing the health disparities gap and improving care.

Position 5: The health care delivery system must be reformed to ensure that patient-centered medical care is easily accessible to racial and ethnic minorities and physicians are enabled with the resources to deliver quality care.

The fragmented, disconnected nature of the American health care system plays a role in creating health disparities among racial and ethnic minorities. Even when minorities have health insurance, they often face significant obstacles in navigating the health care system and cannot access preventive care and disease management benefits available in predominantly white communities. Communities of color usually have fewer health care workers per person than do white communities, and safety-net hospitals and clinics often form the bulk of available providers. Physicians who care for minorities are more often overworked and underpaid compared with those who predominantly treat white patients. ${ }^{86,87}$ Racial and ethnic disparities are exacerbated by provision of lowquality care and the fact that many minorities lack access to a regular health care provider. For instance, African Americans are more likely than whites to use an emergency department, community health clinic, or hospital as their regular source of care. ${ }^{88}$

\section{Patient-Centered Care}

Having access to a usual source of care increases the likelihood that a person will seek preventive care, leading to improved health status over the long run. Unfortunately, Hispanics and African Americans in particular are less likely than whites to have access to a regular source of care ${ }^{89}$ Decreased access to 
ambulatory care means that chronic and acute conditions are less likely to be properly treated, leading to preventable hospitalizations. In addition, physicians that primarily serve African Americans report greater difficulty in delivering high-quality care, referring patients to high-quality specialists, and accessing high-quality imaging services for their patients than do primary care doctors that mostly serve white patients..$^{90}$ Areas with a largely white population had higher-quality care than those with a mostly black and/or Hispanic population, arguing that racial and ethnic disparities can be reduced if overall geographic disparities in health care are mitigated. ${ }^{91}$ Minorities lack sufficient access to preventive care, such as diagnostic screenings and vaccinations. For instance, Hispanics are less likely than other racial and ethnic communities to have cholesterol measurements and colorectal cancer screenings. ${ }^{92}$ Asian Americans, despite having high rates of insurance and income, often have low rates of preventive care. ${ }^{93}$ In addition, minorities are less likely than whites to receive recommended inpatient hospital treatment for pneumonia and heart failure. ${ }^{94}$

Much emphasis has been placed on the need to transform the way health care is delivered to incentivize prevention and patient-centered care rather than reactive care. ACP is a strong proponent of the concept of patient-centered care and believes that such care will improve the bond between doctor and patient, strengthening trust, communication, understanding, and health outcomes. In the ACP paper Achieving Affordable Health Insurance Coverage for All Within Seven Years, the College recommended that the federal government provide dedicated funding to states that have requested federal support for efforts to redesign their health care delivery programs to achieve measurable expansions of health insurance coverage, and to redesign health care financing and delivery systems to emphasize prevention, care coordination, quality, and the use of health information technology through the Patient-Centered Medical Home (PCMH). ${ }^{95}$ The College also expressed its support for service delivery reforms that promote patient-centered, longitudinal, coordinated care in the paper A System in Need of Change: Restructuring Payment Policies to Support Patient-Centered Care. ${ }^{96}$

The College strongly supports wide implementation of the PCMH model, a prevention-focused method of care delivery defined by the Commonwealth Fund as "a health care setting that provides patients with timely, well-organized care, and enhanced access to providers." ${ }^{97}$ Evidence shows that when racial and ethnic minorities receive care through the PCMH model, health disparities are reduced. A survey conducted by the Commonwealth Fund found that patient's access to needed care, rates of routine preventive screening, and chronic care management improved dramatically when they had a medical home. Specifically, $74 \%$ of adults with a medical home surveyed reported that they always received the care they needed, compared with $52 \%$ of adults without a medical home provider. Access disparities among whites and racial and ethnic minorities are lessened when care is received through the medical home model; according to the survey, three fourths of whites, African Americans, and Hispanics with medical homes reported getting the care they needed when they needed it. ${ }^{98}$ Other disparities in indicators of high-quality care, such as receipt of preventive visit reminders and ability to manage chronic disease, also improve when a patient has a medical home. A study by Reschovsky and O'Malley found that primary care physicians who treat many minority patients face unique challenges in the delivery of care compared with physicians who see few minority patients, such as language barriers, poorer health status of the average patient, and reliance on Medicaid or private managed care insurance reimbursements, which 
rarely cover the full cost of delivering care. ${ }^{99}$ Primary care physicians in "highminority" practices also express greater difficulty than those in "low-minority" practices in receiving timely reports from other physicians, and state that inadequate time during office visits affected their ability to provide highquality care. The study concluded that if Medicaid reimbursement rates were increased to those of Medicare, a number of impediments to functioning as a patient's medical home would be alleviated for physicians who see many minority patients.

Minority patients are more likely than whites to receive care in an environment other than a doctor's office or private clinic. ${ }^{100}$ More than 1 out of 5 Hispanics and 1 out of 13 African Americans use a community health center as their regular source of care.$^{101}$ Federally qualified health centers should be supported as a medical home since a disproportionate number of minority patients receive care through these facilities. Alabama, for instance, allows Medicaid patients who participate in the primary care case management system to designate their medical home. ${ }^{102}$

Position 6: A diverse health care workforce that is more representative of those they serve is crucial to promote understanding among health providers and patients, facilitate quality care, and promote equity in the health care system.

A. Education of minority students at all educational levels, especially in the fields of math and science, needs to be strengthened and enhanced to create a larger pool of qualified minority applicants for medical school.

B. Medical and other health professional schools should revitalize efforts to improve matriculation and graduation rates of minority students. ACP supports policies that allow institutions of higher education to consider a person's race and ethnicity as one factor in determining admissions in order to counter the impact of current discriminatory practices and the legacy of past discrimination practices. Programs that provide outreach to encourage minority enrollment in medical and health professional schools should be maintained, reinstated, and expanded.

C. Medical schools need to increase efforts to recruit and retain minority faculty.

D. Efforts should be made to hire and promote minorities in leadership positions in all arenas of the health care workforce.

E. Funding should be continued and increased for programs and initiatives that work to increase the number of physicians and other health care professionals in minority communities.

\section{Workforce}

Racial and ethnic minorities are severely underrepresented among American health care workers. Although African Americans, Hispanics, and Native Americans make up over a quarter of the nation's population, in 2007 African Americans accounted for only 3.5\%, Hispanics 5\%, and Native Americans/ Native Alaskans $0.2 \%$ of physicians. ${ }^{103}$ Similar workforce disparities are found among some Asian subgroups, such as Samoans and Cambodians. ${ }^{104}$ As the nation's population grows more diverse, we will need a workforce that reflects the country's racial and ethnic diversity if the disparity gap is to be closed. 
There are many benefits to having a multicultural workforce. According to the IOM report In the Nation's Compelling Interest, diversity in the health profession is connected to better access for minority patients, improved patient satisfaction, strengthened cultural competence and sensitivity among other health professionals, and overall improved academic performance for students of the health professions.

A number of studies show that underrepresented minority providers are more likely to treat minority patients, improving access to care for underserved populations. Racial and ethnic minority physicians are also more likely to care for the indigent and patients with poor health status than nonunderrepresented minority physicians. ${ }^{105}$ Racial and ethnic minorities also express greater satisfaction with the care they receive if their provider is of the same racial or ethnic background. ${ }^{106}$ While there are immense benefits to racial concordance (the ability for a patient to be treated by a practitioner of the same racial and/or ethnic background) in the health professions, the College does not believe that racial and ethnic minority practitioners should be forced or required in any way to practice in underserved areas or treat primarily minority communities.

\section{Medical Education}

Historically, minority health professions students have faced systematic discrimination that has placed significant barriers to entry into the medical profession. The number of minority medical school graduates lags significantly behind the number of graduating white students. In 2008, only 2,447 of more than 16,000 medical school graduates were African American, Hispanic, and Native American. ${ }^{107}$

Colleges and universities must facilitate a cultural change that puts student body diversity at the core of their mission. Diversity in the health professions student body has a positive effect on all students, not just underrepresented minority students. Cultural competency among physicians and other practitioners is crucial to delivering patient-centered care for racial and ethnic minorities. ${ }^{108}$ Students immersed in a diverse student body may have improved cultural competency and cross-cultural training than those trained in a more racially and ethnically homogenous academic center. Other evidence has shown that interaction with a diverse student body may improve the learning outcomes of all students, not just those studying medicine. Further, health care-related businesses may benefit from a diverse workforce due to the improved relations and effectiveness that can be achieved with improved cultural and linguistic competencies. ${ }^{109}$

In the 2003 edition of this position paper, the College expressed emphatic support for medical school admissions policies that took into account an applicant's race and ethnicity. Medical schools that consider such variables often admit more underrepresented minority students than schools that do not consider an applicant's race or ethnicity. Some evidence shows that minority students admitted under race-conscious policies are as likely as nonminority students to graduate, pass their licensing boards, and achieve professional competency objectives during residency. ${ }^{110}$ In the 1990 s, minority representation in America's medical schools began to increase, and with it, so did opposition from critics of race-conscious admissions policies. In 1996, Californians approved Proposition 209, which prohibited the consideration of race and ethnicity in college admissions at the state's public academic institutions. After the proposition was enacted, the number of applicants and admitted underrepresented minority students dropped precipitously. 
In 2003 the U.S. Supreme Court issued a ruling regarding Grutter v. Bollinger, a case that challenged the University of Michigan's race-conscious admissions policies. The Court decided in favor of the university's affirmative action policy, stating that it did not violate the constitutional rights of nonminority students at the school. More important, the Court affirmed the benefits of a diverse student body not only for academia but also for the nation as a whole, stating that ensuring a diverse mix of students was in the nation's "compelling interest." ACP filed an amicus brief in support of the University of Michigan regarding the Grutter v. Bolinger case. However, in Gratz and Hamacher v. Bollinger et al., in which ACP also filed an amicus brief, the U.S. Supreme Court ruled against Michigan's affirmative action policy, deciding that the undergraduate admissions process arbitrarily favored minority applicants because it automatically distributed points to such applicants. ${ }^{111}$

Efforts to improve the access of racial and ethnic minority students to higher education continue to be threatened. In the face of such challenges, schools have sought to implement other policies that do not rely on affirmative action, such as "percent policies," in which the top academic achievers from high schools are automatically accepted to a college or university regardless of other factors, but these have generally not been successful in raising the number of underrepresented minority admissions. ${ }^{112}$ Once minority students interested in medicine are admitted to undergraduate programs, interventions should take place to ensure that such students reach medical school. Summer mentoring programs established by the Robert Wood Johnson Foundation and similar initiatives by the University of California system have been successful in helping minority students gain admission to medical school. ${ }^{113}$

Since many underrepresented minority students come from modest-income households, efforts must be made to ensure that competent minority students are not forced out of school because of the cost of a professional education. Programs like the federal government's Health Careers Opportunity Program seek to assist disadvantaged students in their health professions education by funding mentoring, outreach, and financial aid, among other activities. In addition, the College is a strong supporter of the programs under Title VII of the Public Health Service Act, which ensure a well-trained and diverse health professions workforce through scholarship and loan repayment programs, faculty development, and grants to improve training and access to care in underserved areas. Unfortunately, the capricious nature of federal appropriations has undermined the ability of these programs to fulfill their respective missions. Academic medical centers must change to ensure that the diversity of the nation is reflected in the student body so that the medical community of the future can be better prepared to care for the different patients it will encounter.

\section{Faculty}

Health professions schools should increase the number of underrepresented minority faculty members. Evidence shows that racial and ethnic minority faculty can have a profound impact on minority students, acting as mentors and providing new scholastic challenges and insights. Medical schools and other health professions institutions should actively recruit such faculty. Once faculty is hired, efforts should be made to address position-related concerns, such as tenure and ability to conduct research. ${ }^{114}$ 


\section{Position 7: Social determinants of health are a significant source of health disparities among racial and ethnic minorities. Inequities in education, housing, job security, and environmental health must be erased if health disparities are to be effectively addressed.}

Health status is influenced not only by access to health care but also by socioeconomic determinants, such as income and availability of nutritious foods, the environmental health of the community, and access to early childhood education. These social factors are well beyond the scope of the health care system, but stakeholders and policymakers must also address such factors that play a part in influencing the health of minority communities.

\section{Income and Education}

An individual's socioeconomic status, particularly their income and education level, is among the myriad factors that influence health. Lower-income individuals, regardless of race or ethnicity, are often in poorer health than those in higher income brackets. An individual's income may influence a number of other determinants of health status, such as one's access to educational opportunities, decent medical care, and affordable housing in a healthy community. ${ }^{115}$ Mortality rates for heart disease are two or three times higher for low-income African American and white individuals than middle-income individuals, and impoverished people are more likely to die prematurely. ${ }^{116,117}$ Still, racial and ethnic disparities exist in the lower- and middle-income brackets as heart disease mortality among African-American women is at least $50 \%$ higher than for comparable white women.

A person's level of education also affects health status. People with higher levels of education live longer and have higher incomes than those with less education. ${ }^{118}$ People with limited education are at a higher risk for cardiovascular disease. ${ }^{119}$ The same study concludes that education may be the strongest predictor of good health and that education may influence health because it facilitates problem-solving and acquisition of socioeconomic skills that may prevent the adoption of adverse habits.

Better-educated people are more likely to have occupations for which they are offered health insurance and to manage their health. Some argue that a significant investment in education, rather than increased focus on medical technology advancement, would alleviate the dramatic health disparities of racial and ethnic minorities. One study found that eight times as many deaths would be averted "if mortality rates among adults with inadequate education were the same as those among individuals at higher education levels." ${ }^{120}$ Further, evidence suggests that reporting of chronic conditions varies based on an individual's education level.

Improved focus on reducing disparities in education must be made if the health disparity gap is also to be closed. Investments in early childhood education and after-school programs for underserved minorities should be made to ensure academic success later in life. Head Start programs, which provide early education to low-income children, have been shown to improve early development. ${ }^{121}$ Evidence shows that black and white children who attended a Head Start program were more likely to receive a measles immunization than those who had not enrolled in such a program. Further, children who were enrolled in early childhood education programs are less likely than those not enrolled to engage in high-risk activities, such as smoking and illicit drug use. ${ }^{122}$ In addition, children who regularly attended after-school programs have markedly increased 
academic performance, including gains in math test scores, compared with students who are unsupervised after school. After-school program participants also show gains in teacher reports of work habits. ${ }^{123}$

Physical fitness education is even more important to combat the increasingly sedentary habits of young children. The Robert Wood Johnson Foundation Commission to Build a Healthier America recommends that education funding should be tied to whether K-12 schools have ensured that children are allotted at least half of their daily recommended physical activity a day. ${ }^{124}$

Unfortunately, a number of significant barriers impede the growth of minority students in the health professions. Among the greatest impediments of social justice faced by racial and ethnic minorities is unequal access to adequate educational opportunities. A lack of educational preparedness - largely the result of inequities in primary education - poses a challenge to students hoping to enter the medical professions. Racial and ethnic minorities are disproportionately low-income and are often educated at schools with insufficient financial resources, less-qualified teaching staff, and fewer advanced courses. Minority students are less likely to graduate compared with white students. One in 5 Latino and 1 in 10 African-American students drop out of high school compared with 1 in 13 white students. ${ }^{125}$

The College supports efforts at the primary education level to improve awareness and interest in the health professions among underrepresented minority students. Education policy experts, academics, and other stakeholders concur that interventions must begin as early as possible to prepare minority students adequately. Recent efforts by the federal government, such as the America COMPETES Act, seek to promote interest in and provide escalated resources for math and science education. In addition to improving outcomes in math and reading education, sustained partnerships to develop and encourage future health professionals should be developed between primary schools, institutions of higher learning, and the medical community. For instance, the Junior Doctors Academy established by the Fresno Unified School District and the University of California prepares disadvantaged students for the rigors of a health professions education. ${ }^{126}$

\section{Public Education Campaigns}

Certain racial and ethnic minority groups have higher rates of chronic disease than whites. For instance, diabetes rates among African Americans, Hispanics, and Native Americans are higher than among whites, and among Native Americans the prevalence is a startling 2.8 times the population average rate. ${ }^{127}$ Diabetes-associated disease rates, such as coronary artery disease and kidney disease, are also higher among some minority groups. As mentioned elsewhere in this paper, ACP strongly supports reforming the health care delivery system towards patient-centered, primary care-focused interventions that seek to prevent, rather than just treat, diseases such as diabetes. In addition to health care delivery system reform, public education campaigns targeted at high-risk groups should also be utilized to educate citizens about healthy living, the importance of prevention, and risk factors that contribute to preventable illness. The Centers for Disease Control and Prevention has initiated the Racial and Ethnic Approaches to Community Health (REACH) program in 40 communities to develop coalitions to address the prevalent disparities in those communities. The REACH program's community-driven focus ensures that campaigns are tailored to the needs of the local population and reflects the culture of the community. In South Los Angeles County, California, age-adjusted death rates 
from diabetes and heart disease for African Americans are higher than the rates for other groups in the county. A likely reason for this disparity is inadequate access to nutritious foods and an overabundance of fast-food restaurants. Further, physical activity opportunity was also less available in South L.A. County than elsewhere in the area. The CDC partnered with community groups in the area and developed a plan to attract more grocery stores and facilitate physical activity. In addition, the Los Angeles City Council approved a measure to prohibit new fast-food restaurants in certain South L.A. areas for at least 1 year. ${ }^{128}$

\section{Marketing of Harmful Products}

The 2003 edition of this paper noted that the marketing of harmful products, such as tobacco, alcohol, and unhealthy food to minority populations contributes to the higher morbidity and chronic disease rates in minority populations. Since then, there have been some strides in curbing marketing targeted to minorities, but the problem still exists and threatens to undermine efforts to close the disparities gap. In 2008, a higher percentage of non-Hispanic black men used tobacco compared with whites. ${ }^{129}$ In 1998, the U.S. Surgeon General released a report documenting how tobacco companies market cigarettes more heavily to minorities and especially how menthol cigarettes, a more harmful type of cigarette, are overwhelmingly targeted at minority communities. ${ }^{130}$ Since the Surgeon General's report was issued over a decade ago, little has changed regarding the marketing of such damaging products. From 1998 to 2005 , money spent on magazine advertising for menthol cigarettes has increased from $13 \%$ of total advertising expenditures to $49 \% .{ }^{131}$ African Americans are disproportionately diagnosed with tobacco-related illness even though the percentage of African Americans who smoke is similar to that of whites. ${ }^{132}$

ACP has supported legislative efforts to empower the Food and Drug Administration to regulate tobacco products. On June 22, 2009, President Obama signed the Family Smoking Prevention and Tobacco Control Act, granting the FDA authority to limit the amount of nicotine in tobacco products, curb marketing of tobacco products to minors, ban use of misleading labeling such as the words "low-tar" and "light," and other steps to regulate the tobacco industry. ${ }^{133}$ In addition to tobacco products, evidence shows that some minority groups are exposed to a significant level of unhealthy food marketing. Obesity rates among African Americans and Hispanics are higher than those of whites, and much of this can be attributed to diet. ${ }^{134}$ Advertisements for unhealthy foods, such as soda and candy, are aired at a higher rate during television shows that are popular among African Americans compared with those intended for the general audience. ${ }^{135}$

According to the National Institutes of Health, some minority groups report higher levels of alcohol use than whites. African-American youths were disproportionately exposed to more alcohol marketing through magazines in 2004, as well as certain malt liquor radio advertisements. ${ }^{136}$ Hispanic youths were exposed to more alcohol advertisements per capita than other youths in general. ${ }^{137}$ In the IOM report Reducing Underage Drinking: A Collective Responsibility, the IOM states that the alcoholic beverage industry has a societal obligation to cease marketing that appeals to youngsters. ${ }^{138}$ 


\section{Violence and Crime}

Violence and crime have a disproportionate impact on minority neighborhoods. ${ }^{139}$ The perception of neighborhood safety is positively associated with physical exercise, an effect more noted in minority than white neighborhoods. Neighborhoods with a higher incidence of violent crime are less likely to have quality recreational facilities and grocery stores offering better nutritional options, thus promoting better dietary choices. ${ }^{140}$ Additionally, neighborhoods with a higher incidence of crime are also less likely to have convenient medical facilities for primary care services, exacerbating the difficulties with health care access.

Position 8: Efforts must be made to reduce the effect of environmental stressors that disproportionately threaten to harm the health and well-being of racial and ethnic communities.

An individual's environment can have a significant impact on his or her overall health status. Twenty-five percent of preventable illnesses worldwide are tied to poor environmental quality. ${ }^{141}$ Environmental dangers, such as poor air quality or rampant lead contamination, can harm the health of the community. Housing segregation of low-income minorities is a likely contributor to the elevated rate of exposure to environmental stressors as poor and/or racial and ethnic minorities often live close to "noxious land use" areas, such as industrial sites or hazardous dumping areas. ${ }^{142,143}$ For instance, a study found that between 1961 and 1998, an above-average percentage of minority residents of New York City resided within a designated manufacturing zone. ${ }^{144}$ Efforts had been made to expand manufacturing zones in areas with a high proportion of minority residents, below-average incomes, and lower-than-average rates of home ownership. Similarly, people in areas where agriculture is the prominent industry have expressed concern about the effects of exposure to pesticides, fertilizers, and other chemicals used in farming. ${ }^{145}$ Racial and ethnic minorities are disproportionately exposed to harmful environmental toxins in their communities, workplaces, and schools. ${ }^{146}$ Asthma rates, among African Americans in particular, abound in areas where environmental dangers persist. In some areas of the country, one in four African Americans is diagnosed with asthma, a chronic respiratory disease. ${ }^{147}$ Factors influencing asthma include exposure to air pollutants, like automobile and power plant emissions. As such, studies have shown that children who live near freeways are more likely to be diagnosed with asthma than other youths. Other research shows that a disproportionate number of Hispanics and Asian and Pacific Islanders reside in areas that fail to meet air quality level standards. ${ }^{148}$ In addition, other toxic pollutants, such as mercury, are disproportionately found in women of certain racial and ethnic minorities. Exposure to mercury can cause neurologic damage in fetuses and children and may have a negative effect on the body's nervous immune and cardiovascular systems. ${ }^{149}$

Addressing health disparities that are the effect of environmental stressors is a complex and difficult task. Despite growing attention in the 1990s from the federal government through the establishment of the Environmental Protection Agency's Office of Environmental Equity (later renamed Office of Environmental Justice), as well as academic stakeholders, such as the IOM, more action needs to be taken to monitor and rectify the harmful effect of environmental stressors on minority communities. Targeting the underlying causes of exposure to environmental dangers, such as housing segregation, income inequality, the community 
effects of violent crime, and air and water pollution, would probably reduce current patterns of illness. In addition, policymakers should develop a set of measures to track environmental stressors and how they contribute to the health disparities of racial and ethnic minorities.

\section{Position 9: More research and data collection related to racial and eth- nic health and health care disparities is needed to empower stake- holders to better understand and address the problem of disparities.}

While research into the existence and effects of racial and ethnic health care disparities has grown in the past decade, more research and coordinated data collection are needed to fully understand the scope of the problem and guide potential solutions. Early efforts to collect data on health disparities, such as the Healthy People 2010 initiative and the National Healthcare Disparities Report (NHDR), have yielded substantial insight into the prevalence of racial and ethnic health disparities, but gaps still exist. For instance, the 2006 NHDR was unable to gather substantial data quality and access data measures for the Native Hawaiian or other Pacific Islander classification and had similar difficulty producing data on Asian/Pacific Islander and individuals listing two or more racial classifications. ${ }^{150}$ The success of other initiatives, such as the Health Disparities Collaborative, which seeks to address racial and ethnic health disparities through improved linguistic and culturally competent primary care access delivered through federally qualified health centers, has been difficult to determine because data regarding the initiative's effect on disparities has not been directly measured. ${ }^{151}$

In 1998, the Office of Management and Budget (OMB) released standards for racial and ethnic disparities data collection; however, these measures have been criticized in part because they fail to adequately reflect racial and ethnic subgroups, such as the Vietnamese within the Asian/Pacific Islander category. ${ }^{152}$ In response to these concerns and others related to the confusion of tracking disparities data, AHRQ commissioned the IOM to study and release recommendations on the subject. The result of that request, 2009's Race, Ethnicity, and Language Data: Standardization for Health Care Quality Improvement, recommended that more ethnicity subcategory options be offered in addition to the OMB racial and ethnic categories. ${ }^{153}$ Since not all subcategories are relevant to all areas of the nation, categories that reflect the local population can be separated from the national data to ensure compatibility. The IOM also recommended that data be collected on a patient's preferred language to better determine language proficiency and language preference during health care encounters. Further, use of electronic health records systems will facilitate coordination and data comparisons across systems and care settings.

Legislative efforts at the federal level to improve data collection have recently been signed into law. The Medicare Improvements for Patients and Providers Act of 2008 directs the Secretary of HHS to determine best practices in the collection of racial and ethnic health care disparities in Medicare beneficiaries and release them to Congress for implementation. ${ }^{154}$

Additionally, a number of states have taken action to increase the collection of racial and ethnic health data. Massachusetts and California have mandated health plans to collect such data. Massachusetts also requires hospitals to collect racial and ethnic patient health data. In addition, New Jersey's state government and hospitals have partnered to compile data. While partnerships are useful, legislation requiring data collection has the most significant impact on action to increase collaboration across systems and providers. ${ }^{155}$ 
More research is needed into the effects of environmental stressors on health status. Payne-Sturges and Gee recommend identifying measures that include such focus areas as residential segregation, drinking water quality, pesticide contamination, and additional emerging issues. ${ }^{156}$ The IOM reached a similar conclusion that data on environmental effects on health was not abundant and that more research was needed to determine the relationship between environmental stressors and their effect on health status. The report further recommended that federal, state, and local public health agencies coordinate their efforts to collect data on environmental health information and its link to community health. ${ }^{157}$

\section{Conclusion}

Racial and ethnic disparities in health care result from the interaction of multiple complex factors, including past and current discrimination in health care, genetics, unequal educational opportunity, income and health care access disparities, cultural beliefs, and community systems. There is no easy solution to closing the health care disparities gap, but it is a moral imperative that appropriate resources be brought to bear to address these differences. The College believes that while improving access to quality care, reforming the health care delivery system, improving cultural and linguistic understanding, diversifying the health care workforce, and improving the inequities in the social influences of health may not fully close the disparities gap, achieving these worthy goals would dramatically improve the lives of all people and the future of the nation. 


\section{References}

1. Institute of Medicine. Unequal Treatment: Confronting Racial and Ethnic Disparities in Health Care. Washington, DC: National Academies Press; 2002.

2. Institute of Medicine. Unequal Treatment: Confronting Racial and Ethnic Disparities in Health Care. Washington, DC: National Academies Press; 2002.

3. Herbert P et al. When Does A Difference Become a Disparity? Conceptualizing Racial and Ethnic Disparities in Health. Health Affairs. 2008: 374-382.

4. Lurie $\mathrm{N}$ and Dubowitz T. Health Disparities and Access to Health. FAMA. March 14, 2007: 1118-1121.

5. James C et al. Putting Women's Health Care Disparities on the Map: Examining Racial and Ethnic Disparities at the State Level. Kaiser Family Foundation. June 2009. Accessed at http://www.kff.org/ minorityhealth/upload/7886.pdf on November 2, 2009.

6. I. H. Zuckerman, P. T. Ryder, L. Simoni-Wastila et al., "Racial and Ethnic Disparities in the Treatment of Dementia Among Medicare Beneficiaries," Journal of Gerontology, October 2008 63B(5):S328-33.

7. Blendon R et al. Disparities in Physician Care: Experiences and Perceptions of a Multi-Ethic America. Health Affairs. 2008;27:507-517.

8. Heron M et al. Deaths: Final Data for 2006. National Vital Statistics Reports; April 17, 2009. Accessed at http://www.cdc.gov/nchs/data/nvsr/nvsr57/nvsr57_14.pdf on August 17, 2009.

9. MacDorman MF and Mathews TJ. Recent Trends in Infant Mortality in the United States. NCHS Data Brief, No. 9. October 2008. Accessed at http://www.cdc.gov/nchs/data/databriefs/db09.pdf on September 15, 2009.

10. Williams RA. Eliminating healthcare disparities in America: beyond the IOM report. 2007. Accessed at http://books.google.com/books?id=AxwUqId5hwcC\&dq=health+disparity+life+ expectancy+blacks+and+whites\&source=gbs_navlinks_s on August 17, 2009.

11. Satcher D et al. What If We Were Equal? A Comparison of the Black-White Mortality Gap in 1960 and 2000. Health Affairs. 2005;24(2):459-464.

12. Acevedo-Garcia D et al. Towards a Policy-Relevant Analysis of Geographic and Racial/Ethnic Disparities in Child Health. Health Affairs. 2008: 321-333.

13. Institute of Medicine. Unequal Treatment: Confronting Racial and Ethnic Disparities in Health Care. Washington, DC: National Academies Press; 2002.

14. Wilensky G and Satcher D. Don't Forget About the Social Determinants of Health. Health Affairs [serial online]. 2009: w-194-198. Accessed at http://www.allhealth.org/briefingmaterials/ SocialDeterminantsofHealth--HAWilenskySatcher-1472.pdf on August 17, 2009.

15. American College of Physicians. Strategic Plan., Strategic Themes and Objectives. July 2009. Accessed at $\mathrm{N}: \backslash \mathrm{RPE} \backslash$ Online Documents $\backslash$ Planning $\backslash$ Strategic Plan $\backslash 2009-10$.pdf on 15 September 2009.

16. Kaiser Family Foundation. Key Facts: Race, Ethnicity, and Medical Care. January 2007. Accessed at http://www.kff.org/minorityhealth/upload/6069-02.pdf on August 24, 2009.

17. U.S. Census Bureau. Income, Poverty, and Health Insurance Coverage in the United States: 2008. U.S. Census Bureau News. September 10, 2009. Accessed at http://www.census.gov/ Press-Release/www/releases/archives/income_wealth/014227.html on November 3, 2009.

18. Testimony of Marsha Lillie-Blanton, Dr.P.H., Senior Advisor on Race, Ethnicity, and Health Care, Henry J. Kaiser Family Foundation, before the House Ways and Means Subcommittee on Health. June 10, 2008.

19. Agency for Healthcare Research and Quality. 2007 National Healthcare Disparities Report-At a Glance. Rockville, MD; February 2008. Accessed at http://www.ahrq.gov/qual/nhdr07/Glance.htm on August 24, 2009.

20. Lillie-Blanton $M$ and Hoffman C. The Role of Health Insurance Coverage in Reducing Racial/Ethnic Disparities in Health Care. Health Affairs. 2005; 24:400-401. 
21. Institute of Medicine. Coverage Matters: Insurance and Health Care. Washington: National Academies Press; 2001.

22. Institute of Medicine. America's Uninsured Crisis: Consequences for Health and Health Care. Washington: National Academies Press; 2009. Accessed at http://books.nap.edu/openbook.php? record_id=12511\&page=3 on August 24, 2009.

23. Health Disparities: A Case for Closing the Gap. Healthreform.gov. 2009. Accessed at http://www.healthreform.gov/reports/healthdisparities/index.html on August 24, 2009.

24. Lyke B. The Tax Exclusion for Employer-Provided Health Insurance: Policy Issues Regarding the Repeal Debate. Washington DC. http://assets.opencrs.com/rpts/RL34767_20081121.pdf.

25. Kaiser Family Foundation. Key Facts: Race, Ethnicity, and Medical Care. January 2007. Accessed at http://www.kff.org/minorityhealth/upload/6069-02.pdf on August 24, 2009.

26. Kaiser Family Foundation. Key Facts: Race, Ethnicity, and Medical Care. January 2007. Accessed at http://www.kff.org/minorityhealth/upload/6069-02.pdf on August 24, 2009.

27. Berndt J and James C. Effects of the Economic Downturn on Communities of Color. Kaiser Family Foundation. July 2009. Accessed at http://www.kff.org/minorityhealth/upload/7953.pdf on August 24, 2009.

28. Families USA. Health Care Reform: Critical to Closing the Gap for Communities of Color. March 2009. Accessed at http://www.familiesusa.org/assets/pdfs/health-reform/closing-the-gap.pdf on August 24, 2009.

29. Families USA. Health Coverage in Communities of Color: Talking about the New Census numbers. September 2008. Accessed at http://www.familiesusa.org/assets/pdfs/minority-health-andthe-census-numbers.pdf on August 24, 2009.

30. Dorn S et al. Medicaid, SCHIP, and Economic Downturn: Policy Changes and Policy Responses. Kaiser Family Foundation. April 2008. Accessed at http://www.kff.org/medicaid/upload/7770.pdf on August 25, 2009.

31. Kaiser Family Foundation. Supplemental Coverage Among Medicare Beneficiaries, by Race/ Ethnicity, 2006. Presentation Slide. Accessed at http://facts.kff.org/chart.aspx?ch=519 on August 25, 2009.

32. Testimony of Marsha Lillie-Blanton, Dr.P.H., Senior Advisor on Race, Ethnicity, and Health Care, Henry J. Kaiser Family Foundation, before the House Ways and Means Subcommittee on Health. June 10, 2008.

33. Urban Institute, Going Without: America's Uninsured Children. Washington: Robert Wood Johnson Foundation, August 2005. Accessed at http://www.rwjf.org/files/newsroom/ckfresearchreportfinal.pdf on August 25, 2009.

34. Smedley B. Moving Beyond Access: Achieving Equity in State Health Care Reform. Health Affairs. 2008; 27:447-455.

35. Children's National Medical Center. Final SCHIP Bill Summary. February 4, 2009. Accessed at http://www.childrensnational.org/files/PDF/advocacy/OnCapitolHill/SCHIPresolution.pdf on August 25, 2009.

36. American College of Physicians. Achieving Affordable Health Insurance Coverage for all Within Seven Years: A Proposal from America's Internists, Updated 2008. Philadelphia: American College of Physicians; 2008: Position Paper.

37. American College of Physicians. Achieving A High Performance Health Care System With Universal Access: What The USA Can Learn From Other Countries, 2007. Philadelphia: American College of Physicians; October 2007. Position paper.

38. Peterson E and Yancy CW. Eliminating Racial aand Ethnic Disparities in Cardiac Care. NEFM. 2009;360:1172.

39. Lillie-Blanton et al. Racial/Ethnic Differences in Cardiac Care: The Weight of the Evidence. Kaiser Family Foundation and American College of Cardiology. October 2002. 
40. Virnig B et al. A Matter of Race: Early- Versus Late-Stage Cancer Diagnosis. Health Affairs. 2009; 28(1):160.

41. Blendon R et al. Disparities in Physician Care: Experiences and Perceptions of a Multi-Ethic America. Health Affairs. 2008;27:507-517.

42. Kaiser Family Foundation. "Changes in Quality of Care Disparities Over Time: Summary by Race/Ethnicity." Kaiser Family Foundation presentation slide. May 19, 2008. Accessed at http://facts.kff.org/chart.aspx?ch=375 on November 3, 2009.

43. American College of Physicians. Controlling Health Care Costs While Promoting the Best Possible Outcomes. Philadelphia: American College of Physicians; 2009: Policy Monograph.

44. Wu E and Martinez M. Taking Cultural Competency from Theory to Action. Commonwealth Fund. October 2006. Access at http://www.commonwealthfund.org/ /media/Files/Publications/ Fund\%20Report/2006/Oct/Taking\%20Cultural\%20Competency\%20from\%20Theory\%20to\%20 Action/Wu_takingcultcomptheoryaction_964\%20pdf.pdf on August 25, 2009.

45. Chen P. Doctor and Patient: Bridging the Culture Gap. New York Times. July 16, 2009. Accessed at http://www.nytimes.com/2009/07/16/health/16chen.html?_r=2\&pagewanted=1\&hpw on August 27, 2009.

46. Office of Minority Health. National Standards on Culturally and Linguistically Appropriate Services (CLAS). Accessed at http://www.omhrc.gov/templates/browse.aspx?lvl=2\&lvliD=15 on August 25, 2009.

47. Beach MC et al. The Role and Relationship of Cultural Competence and Patient-Centeredness in Health Care Quality. Commonwealth Fund. October 17, 2006. Accessed at http://www. commonwealthfund.org/Content/Publications/Fund-Reports/2006/Oct/The-Role-and-Relationshipof-Cultural-Competence-and-Patient-Centeredness-in-Health-Care-Quality.aspx on August 25, 2009.

48. Betancourt J et al. Cultural Competency and Health Care Disparities: Key Perspectives and Trends. Health Affairs. 2005; 24:499-505.

49. Barrett S, Dyer C, and Westpheling K. Language Access: Understanding the Barriers and Challenges in Primary Care Settings. Perspectives from the Field. McLain, VA: Association of Clinicians for the Underserved, May 2008.

50. Youdelman M. The Medical Tongue: U.S. Laws and Policies on Language Access. Health Affairs. 2008; 27:424-433.

51. Flores G. Language Barriers to Health Care in the United States. NE7M. 2006;355:229-231.

52. American College of Physicians. Language Services for Patients with Limited English Proficiency: Results of a National Survey of Internal Medicine Physicians. Philadelphia: American College of Physicians; 2006: Position Paper.

53. Barrett S, Dyer C, and Westpheling K. Language Access: Understanding the Barriers and Challenges in Primary Care Settings. Perspectives from the Field. McLain, VA: Association of Clinicians for the Underserved, May 2008.

54. American College of Physicians. Language Services for Patients with Limited English Proficiency: Results of a National Survey of Internal Medicine Physicians. Philadelphia: American College of Physicians; 2006: Position Paper.

55. Smedley B. Moving Beyond Access: Achieving Equity in State Health Care Reform. Health Affairs. 2008; 27:447-455.

56. Youdelman M. The Medical Tongue: U.S. Laws and Policies on Language Access. Health Affairs. 2008; 27:424-433.

57. Youdelman M. The Medical Tongue: U.S. Laws and Policies on Language Access. Health Affairs. 2008; 27:424-433.

58. Baker DW, Parker RM, Williams MV, Coates WC, Pitkin K. Use and effectiveness of interpreters in an emergency department. FAMA 1996;275:783-788. 
59. American College of Physicians. Language Services for Patients with Limited English Proficiency: Results of a National Survey of Internal Medicine Physicians. Philadelphia: American College of Physicians; 2006: Position Paper.

60. Youdelman M. The Medical Tongue: U.S. Laws and Policies on Language Access. Health Affairs. 2008; 27:424-433.

61. Youdelman M. Medicaid and SCHIP Reimbursement Models for Language Services. Washington DC: National Health Law Program. March 2007.

62. American College of Physicians. Language Services for Patients with Limited English Proficiency: Results of a National Survey of Internal Medicine Physicians. Philadelphia: American College of Physicians; 2006: Position Paper.

63. ACP. Language Access in Health Care: Statement of Principles. October 24, 2004. Accessed on http://www.acponline.org/advocacy/where_we_stand/access/language.pdf.

64. U.S. Department of Health and Human Services Office of Disease Prevention and Health Promotion. Health Literacy - Fact Sheet: The Basics. Accessed at http://www.health.gov/ communication/literacy/quickguide/factsbasic.htm\#one on August 26, 2009.

65. Institute of Medicine. Health Literacy: A Prescription to End Confusion. Washington: National Academies Press; 2004. Accessed at http://www.nap.edu/catalog.php?record_id=10883\#toc on August 26, 2009.

66. Institute of Medicine. Health Literacy: A Prescription to End Confusion. Washington: National Academies Press; 2004. Accessed at http://www.nap.edu/catalog.php? record_id=10883\#toc on August 26, 2009.

67. Hoffman C and Tolbert J. Health savings Accounts and High Deductible Health Plans: Are They An Option for Low-Income Families? Kaiser Family Foundation. October 2006. Accessed at http://www.kff.org/uninsured/upload/7568.pdf on August 26, 2009.

68. Blendon R et al. Disparities in Physician Care: Experiences and Perceptions of a Multi-Ethic America. Health Affairs. 2008;27:507-517.

69. U.S. Department of Health and Human Services Office of Disease Prevention and Health Promotion. Health Literacy - Strategies: Improve the Usability of Health Information. Accessed at http://www.health.gov/communication/literacy/quickguide/healthinfo.htm\#three on August 26, 2009.

70. Schillinger D et al. Closing the Loop: Physician Communication with diabetic Patients Who Have Low Health Literacy. Arch Int Med. 2003;163:83-90.

71. Barret SR, Puryear J Sheen, Westpheling K. Health Literacy Practices in Primary Care Settings: Examples from the Field. The Commonwealth Fund, January 2008.

72. Schlotthauer et al. Evaluating Interventions to Reduce Health Care Disparities: An RWJF Program. Health Affairs. 2008; 27:568.

73. Barret SR, Puryear J Sheen, Westpheling K. Health Literacy Practices in Primary Care Settings: Examples from the Field. The Commonwealth Fund, January 2008.

74. Institute of Medicine. Unequal Treatment: Confronting Racial and Ethnic Disparities in Health Care. Washington, DC: National Academies Press; 2002.

75. Institute of Medicine. Unequal Treatment: Confronting Racial and Ethnic Disparities in Health Care. Washington, DC: National Academies Press; 2002.

76. Blendon R et al. Disparities in Physician Care: Experiences and Perceptions of a Multi-Ethic America. Health Affairs. 2008;27:507-517.

77. Hutchinson T and Dobkin P. Mindful Medicine practice: just another fad? Canadian Family Physician. 2009;55:778-779.

78. Fox RC. Cultural Competence and the Culture of Medicine. NEFM. 2005;353:1316-1319. 
79. Goode T, Dunne MC, Bronheim M. The Evidence Base for Cultural and Linguistic Competency in Health Care. National Center for Cultural Competence; Center for Child and Human Development, Georgetown University; the Commonwealth Fund. October 2006. Accessed at http://www.commonwealthfund.org/ /media/Files/Publications/Fund\%20Report/2006/Oct/The\% 20Evidence\%20Base\%20for\%20Cultural\%20and\%20Linguistic\%20Competency\%20in\%20Healt h\%20Care/Goode_evidencebasecultlinguisticcomp_962\%20pdf.pdf on August 27, 2009.

80. Brotherton SE, Rockey P, and Etzel S. US Graduate Medical Education, 2003-2004. FAMA. 2004; 292:1032-1037.

81. Weissman et al. Resident Physicians' Preparedness to Provide Cross-Cultural Care. FAMA. 2005; 294:1058-1067.

82. Weissman et al. Resident Physicians' Preparedness to Provide Cross-Cultural Care. FAMA. 2005; 294:1058-1067.

83. Kumas-Tan $\mathrm{Z}$ et al. Measures of Cultural Competence: Examining Hidden Assumptions. Academic Medicine. 2007; 82:548-557.

84. Betancourt J et al. Cultural Competency and Health Care Disparities: Key Perspectives and Trends. Health Affairs. 2005; 24:499-505.

85. Association of American Medical Colleges. Cultural Competence Education. 2005. Accessed at http://www.aamc.org/meded/tacct/culturalcomped.pdf on August 27, 2009

86. Bach $\mathrm{P}$ et al. Primary Care Physicians Who Treat Blacks and Whites. NE7M. 2004;351:575-584.

87. Reschovsky J and O'Malley AS. Do Primary Care Physicians Treating Minority Patients Report Problems Delivering High-Quality Care? Health Affairs. 2008;27:w222-w231.

88. Halbert CH et al. Racial Differences in Trust in Health Care Providers. Arch Inten Med. 2006; 166:896-901.

89. Zuvekas SH and Taliaferro GS. Pathways to Access: Health Insurance, The Health Care Delivery System, And Racial/Ethnic Disparities, 1996-1999. Health Affairs. 2003; 22: 139-153.

90. Bach P et al. Primary Care Physicians Who Treat Blacks and Whites. NE7M. 2004;351:575-584.

91. Baicker K et al Geographic Variation in Health Care and the Problem of Measuring Racial Disparities. Perspectives in Biology and Medicine. 2005;48:S42.

92. Agency for Healthcare Research and Quality. National Healthcare Disparities Report. 2005.

93. H. Mead, L. Cartwright-Smith, K. Jones, C. Ramos, K. Woods, and B. Siegel, Racial and Ethnic Disparities in U.S. Health Care: A Chartbook, The Commonwealth Fund, March 2008. Accessed at http://www.commonwealthfund.org/ /media/Files/Publications/Chartbook/2008/Mar/Racial\% 20and\%20Ethnic\%20Disparities\%20in\%20U\%20S\%20\%20Health\%20Care\%20\%20A\%20Char tbook/Mead_racialethnicdisparities_chartbook_1111\%20pdf.pdf on September 17, 2009.

94. H. Mead, L. Cartwright-Smith, K. Jones, C. Ramos, K. Woods, and B. Siegel, Racial and Ethnic Disparities in U.S. Health Care: A Chartbook, The Commonwealth Fund, March 2008

95. American College of Physicians. Achieving Affordable Health Insurance Coverage for All Within Seven Years: A Proposal from America's Internists, Updated 2008. Philadelphia: American College of Physicians; 2008: Position Paper.

96. American College of Physicians. A System in Need of Change: Restructuring Payment Policies to Support Patient-Centered Care. Philadelphia: American College of Physicians; 2006. Position Paper.

97. A. C. Beal, M. M. Doty, S. E. Hernandez, K. K. Shea, and K. Davis, Closing the Divide: How Medical Homes Promote Equity in Health Care: Results From The Commonwealth Fund 2006 Health Care Quality Survey, The Commonwealth Fund, June 2007.

98. A. C. Beal, M. M. Doty, S. E. Hernandez, K. K. Shea, and K. Davis, Closing the Divide: How Medical Homes Promote Equity in Health Care: Results From The Commonwealth Fund 2006 Health Care Quality Survey, The Commonwealth Fund, June 2007. 
99. Reschovsky J and O'Malley AS. Do Primary Care Physicians Treating Minority Patients Report Problems Delivering High-Quality Care? Health Affairs. 2008;27:w222-w231.

100. Gaskin D et al. Examining Racial and Ethnic Disparities in Site of Usual Source of Care. Journal of the National Medical Association. 2007;99:22-30.

101. A. C. Beal, M. M. Doty, S. E. Hernandez, K. K. Shea, and K. Davis, Closing the Divide: How Medical Homes Promote Equity in Health Care: Results From The Commonwealth Fund 2006 Health Care Quality Survey, The Commonwealth Fund, June 2007.

102. Takash M and Osius E. Policies and Strategies to Make Medicaid Managed Care Work for FQHCs: Experiences from Two States. National Academy for state Health Policy. March 2009. Accessed at http://www.nashp.org/files/AL_MI_MMC_final.pdf on September 1, 2009.

103. American Medical Association. Physician Statistics: Total Physicians by Race/Ethnicity - 2006. Accessed at http://www.ama-assn.org/ama/pub/about-ama/our-people/member-groups-sections/ minority-affairs-consortium/physician-statistics/total-physicians-raceethnicity-2006.shtml on September 2, 2009.

104. Grumbach K and Mendoza R. Disparities in human Resources: Addressing the Lack of Diversity in the Health Professions. Health Affairs. 2008;27:413-422.

105. Health Resources and Services Administration. The Rationale for Diversity in the Health Professions: A Review of the Evidence. October 2006. Accessed at http://bhpr.hrsa.gov/ healthworkforce/reports/diversity/default.htm on September 2, 2009.

106. Cooper-Patrick et al. Race, Gender, and Partnership in the Patient-Physician Relationship. FAMA. 1999;282:583-589.

107. Statehealthfacts.org. United States: Distribution of Medical School Graduates by Race/Ethnicity, 2008. Accessed at http://www.statehealthfacts.org/profileind.jsp?ind $=454 \&$ cat $=9 \& \operatorname{rgn}=1$ on September 17, 2009.

108. Cohen JJ. The Consequences of Premature Abandonment of Affirmative Action in Medical School Admissions. FAMA. 2003; 289:1143-1149.

109. Grumbach K and Mendoza R. Disparities in Human Resources: Addressing the Lack of Diversity in the Health Professions. Health Affairs. 2008;27:413-422.

110. Davidson RC and Lewis EL. Affirmative Action and Other Special Consideration Admissions at the University of California, Davis School of Medicine. FAMA. 1997;278:1153-1158.

111. AAMC. Assessing Medical School Admissions Policies: Implications of the U.S. Supreme Court's Affirmative-Action Decisions. September 2003.

112. IOM. In the Nation's Compelling Interest: Ensuring Diversity in the Health-Care Workforce. Washington: National Academies; 2004.

113. Grumbach K and Mendoza R. Disparities in Human Resources: Addressing the Lack of Diversity in the Health Professions. Health Affairs. 2008;27:413-422.

114. IOM. In the Nation's Compelling Interest: Ensuring Diversity in the Health-Care Workforce. Washington: National Academies; 2004.

115. Adler N and Newman K. Socioeconomic Disparities in Health: Pathways and Policies. Health Affairs. 2002; 21(2):66.

116. Williams D and Jackson P. Social Sources of Racial Disparities in Health. Health Affairs. 2005;24(2):325-334.

117. Agency for Healthcare Research and Quality. 2008 National Healthcare Disparities Report. March 2009. Accessed at http://www.ahrq.gov/QUAL/nhdr08/nhdr08.pdf on November 12, 2009.

118. Braveman P. Reaching America's Health Potential: A State-by-State Look at Adult Health. A Presentation. Robert Wood Johnson Foundation. May 15, 2009. Accessed at http://www. allhealth.org/briefing_detail.asp?bi=155 on September 2, 2009. 
119. Winkleby M et al. Socioeconomic Status and Health: How education, Income, and Occupation Contribute to Risk Factors for Cardiovascular Disease. Am fournal Public Health. 1992; 82:816.

120. Woolf et al. Giving Everyone the Health of the Educated: An Examination of Whether Social Change Would Save More Lives Than Medical Advances. Am Fournal Public Health. 2007; 97:679.

121. Wilensky GR and Satcher D. Don't Forget the Social Determinants of Health. Health Affairs. 2009;28:w194-198.

122. Schoeni RF. Making Americans Healthier: Social and Economic Policy as Health Policy. New York: Russell Sage Foundation. 2008.

123. Vandell DL et al. Outcomes Linked to High-Quality Afterschool Programs: Longitudinal Findings from the Study of Promising Afterschool Programs. October 2007. Tirodkar.

124. Robert Wood Johnson Foundation Commission to Build a Healthier America. Physical Activity. 2009. Accessed at http://www.commissiononhealth.org/PhysicalActivity.aspx on September 7, 2009.

125. Orfield G et al. Losing Our Future: How Minority Youth Are Being Left Behind by the Graduation Rate Crisis. The Urban Institute: 2004. Accessed at http://www.urban.org/UploadedPDF/ 410936_LosingOurFuture.pdf on September 2, 2009.

126. University of California, San Francisco, Fresno. USCF Fresno Junior Doctors Academy. Accessed at http://www.fresno.ucsf.edu/latinocenter/jr-dr-academy.htm on September 2, 2009.

127. AHRQ. Diabetes Disparities Among Racial and Ethnic Minorities: Fact Sheet.

128. CDC. Chronic Disease - REACH - At A Glance. 2009. Accessed at http://www.cdc.gov/ NCCdphp/publications/AAG/reach.htm on September 7, 2009

129. American Lung Association. Smoking Rates Among African Americans. 2009. Access at http://www.lungusa.org/stop-smoking/about-smoking/facts-figures/african-americans-and-tobacco. html\#2 on December 17, 2009.

130. CDC. Tobacco Use Among U.S. Racial/Ethnic Minority Groups. A Report of the U.S. Surgeon General, 1998. Accessed at http://www.cdc.gov/tobacco/data_statistics/sgr/1998/complete_report/ index.htm on September 7, 2009.

131. Testimony of Gregory N. Connolly before the U.S. Senate Committee on Health, Education, Labor, and Pensions. February 27, 2007. Accessed at http://help.senate.gov/Hearings/ 2007_02_27/Connolly.pdf on September 7, 2009.

132. American Lung Association. Smoking Rates Among African Americans. 2009. Access at http://www.lungusa.org/stop-smoking/about-smoking/facts-figures/african-americans-and-tobacco.html\#2 on December 17, 2009.

133. Associated Press. "Obama signs sweeping anti-smoking bill." June 22, 2009. Accessed at http://www.msnbc.msn.com/id/31481823/from/ET/ on September 7, 2009.

134. American Obesity Association. Obesity in Minority Populations. Accessed at http://obesity1. tempdomainname.com/subs/fastfacts/Obesity_Minority_Pop.shtml on September 7, 2009.

135. Tirodkar M and Jain A. Food Messages on African American Television Shows. Am fournal Public Health. 2003;93:439-441.

136. CAMY.org. African-American Youth and Alcohol Advertising. June 2006. Accessed at http://camy.org/factsheets/index.php?FactsheetID=11 on September 7, 2009.

137. CAMY.org. Hispanic Youth and Alcohol Advertising. October 2005. Accessed at http://camy.org/factsheets/index.php?FactsheetID $=10$.

138. IOM. Reducing Underage Drinking: A Collective Responsibility. Washington: The National Academies, 2003.

139. Center for Disease Control and Prevention. Neighborhood Safety and the Prevalence of Physical Inactivity—Selected States, 1996, Morbidity and Mortality Weekly Report. 1999;48(7):143-146.

140. Cheadle A. et al. Community-Level Comparisons between the Grocery Store Environment and Individual Dietary Practices, Preventive Medicine 1991; 20(2): 250-261. 
141. Healthypeople.gov. Healthy People 2010: Leading health indicators. Accessed at http://www.healthypeople.gov/Document/html/uih/uih_4.htm\#environqual on September 8, 2009.

142. Shavers V and Shavers S. Racism and health inequity among Americans. J Natl Med Assoc. 2006; 98:386-396. Accessed at http://www.pubmedcentral.nih.gov/pagerender.fcgi? artid=2576116\& pageindex $=3$ on September 7, 2009.

143. Maantay J. Zoning, Equity, and Public Health. Am fournal Public Health. 2001;91:1033-1041.

144. Maantay J. Zoning, Equity, and Public Health. Am fournal Public Health. 2001;91:1033-1041.

145, IOM. Toward Environmental Fustice: Research, Education, and Health Policy Needs. Washington: National Academies; 1999.

146. Shavers V and Shavers S. Racism and health inequity among Americans. J Natl Med Assoc. 2006; 98:386-396. Accessed at http://www.pubmedcentral.nih.gov/pagerender.fcgi? artid=2576116\& pageindex=3 on September 7, 2009.

147. Bell J and Standish M. Communities and Health Policy: A Pathway for Change. Health Affairs. 2005;24:339-342.

148. Healthypeople.gov. Healthy People 2010: Leading health indicators. Accessed at http://www. healthypeople.gov/Document/html/uih/uih_4.htm\#environqual on September 8, 2009.

149. Payne-Sturgis D and Gee GC. National environmental health measures for minority and low-income populations: Tracking social disparities in environmental health. Environmental Research. 2006;102:154171. Accessed at http://yosemite.epa.gov/ochp/ochpweb.nsf/content/Disparities2.htm/\$File/ Disparities2.pdf on September 8, 2009.

150. Bilheimer L and Sisk J. Collecting Adequate Data on Racial and Ethnic Disparities in Health: the Challenges Continue. Health Affairs. 2008;27(2):383-391.

151. Higgins PC and Taylor EF. Measuring Racial and Ethnic Disparities in Health Care: Efforts to Improve Data Collection. Mathematica Policy Research, Inc. May 2009. Accessed at http://www. mathematica-mpr.com/publications/PDFs/health/disparitieshealthcare.pdf on September 9, 2009.

152. Higgins PC and Taylor EF. Measuring Racial and Ethnic Disparities in Health Care: Efforts to Improve Data Collection. Mathematica Policy Research, Inc. May 2009. Accessed at http://www. mathematica-mpr.com/publications/PDFs/health/disparitieshealthcare.pdf on September 9, 2009.

153. IOM. Race, Ethnicity, and Language Data: Standardization for Health Care Quality Improvement. Report Brief. Washington: National Academies. August 2009.

154. Families USA. Medicare Improvements for Patients and Providers Act of 2008: Addressing Racial and Ethnic Health Disparities. November 2008. Accessed at http://www.familiesusa.org/ assets/pdfs/mippa-addressing-disparities_3.pdf on September 9, 2009.

155. Higgins PC and Taylor EF. Measuring Racial and Ethnic Disparities in Health Care: Efforts to Improve Data Collection. Mathematica Policy Research, Inc. May 2009. Accessed at http://www. mathematica-mpr.com/publications/PDFs/health/disparitieshealthcare.pdf on September 9, 2009.

156. Payne-Sturgis D and Gee GC. National environmental health measures for minority and lowincome populations: Tracking social disparities in environmental health. Environmental Research. 2006;102:154-171. Accessed at http://yosemite.epa.gov/ochp/ochpweb.nsf/content/Disparities2. htm/\$File/Disparities2.pdf on September 8, 2009.

157. IOM. Toward Environmental Justice: Research, Education, and Health Policy Needs. Washington: National Academies; 1999. 



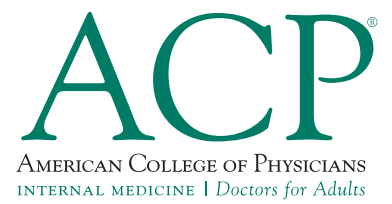

Product \#520701000 